\title{
DEMOCRACIA, CIDADE E ESPAÇOS DE PODER EM ENSAIO SOBRE A LUCIDEZ, DE JOSÉ SARAMAGO
}

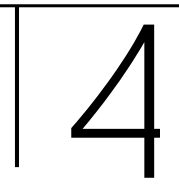

\author{
DEMOCRACY, CITY AND SPACES OF POWER IN \\ ENSAIO SOBRE A LUCIDEZ, BY JOSÉ SARAMAGO
}

\begin{abstract}
VELOSO, Jeymeson de Paula
Doutorando em Estudos da Linguagem pela Universidade Federal do Piauí - UFPI

Mestre em Estudos da Linguagem pela Universidade Federal do Piauí - UFPI

Professor do Instituto Federal do Maranhão - IFMA

E-mail: jeymeson.veloso@ifma.edu.br

ORCID ID: https://orcid.org/0000-0002-7629-2084
\end{abstract}

\section{PINHeIRO, André}

Doutor em Literatura Comparada pela Universidade Federal do Rio Grande do Norte - UFRN

Professor da Universidade Federal do Piauí - UFPI

E-mail: andrepinheiro@ufpi.edu.br

ORCID ID: https://orcid.org/0000-0003-1404-9043

\section{RESUMO}

O principal objetivo deste artigo é analisar as relações estabelecidas entre espaço e poder no romance Ensaio sobre a lucidez, do escritor português José Saramago, tendo como foco de observação o regime democrático delineado na obra. Lançado no ano de 2004, o romance acaba por promover uma análise da cidade como locus de poder, além de tecer severas críticas ao estado democrático contemporâneo. De modo geral, no romance é corrente a ideia de que a democracia praticada atualmente pelos governantes funciona mais como um discurso dissimulador do que como uma forma política capaz de atender aos anseios da população. Dessa forma, Saramago busca revelar as bases ideológicas e os interesses políticos existentes por trás de grupos governamentais para os quais a democracia não passa de um subterfúgio. É importante destacar que todas essas questões políticas estão materializadas na tessitura do espaço ficcional, no modo como a cidade é estruturada na narrativa. Para promover a leitura do regime democrático na contemporaneidade, utilizamos como aporte teórico os trabalhos de Denis Rosenfield (2008) e Simone Goyard-Fabre (2003); já para executar a análise da estrutura espacial da obra, recorremos às sistematizações produzidas por Ozíris Borges Filho (2007) e Luis Alberto Brandão (2013). Concluímos que, no interior de um enredo agonal, determinados espaços funcionam como materialização do poder coercitivo e outros como um ato de resistência contra à barbárie.

Palavras-chave: Espaço Ficcional; democracia; cidade; Saramago. 


\begin{abstract}
We analyze in this article the relations between space and power in the novel Essay on Lucidity, by the portuguese writer José Saramago, focusing on the democratic regime outlined in the text. Released in 2004, the novel promoves an analysis of the city as a locus of power; afterward, it makes severe criticisms of the contemporary democratic state. In general, the novel defends the idea that democracy currently practiced by rulers works more as a dissimulating discourse than as a political form capable of meeting the population's concerns. In this way, Saramago seeks to reveal the ideological bases and the political interests that exist behind the government groups for which democracy is nothing more than a subterfuge. It is noteworthy that all these political issues are materialized in the fictional space, in the way the city is structured in the narrative. To promote the reading of the democratic regime in contemporaneity, we used as theoretical support the works of Denis Rosenfield (2008) and Simone Goyard-Fabre (2003); to carry out the analysis of the spatial structure of the novel, we read the systematizations produced by Oziris Borges Filho (2007) and Luis Alberto Brandão (2013). We conclude that, within an agonal plot, certain spaces function as a materialization of coercive power and others as an act of resistance against barbarism.
\end{abstract}

Keywords: Fictional space; democracy; city; Saramago.

\title{
DEMOCRACIA: O DEUS QUE FALHOU
}

Dentre uma série de peculiaridades estilísticas, a obra do escritor português José Saramago é assinalada pela variedade temática e pela apresentação de tramas inusitadas, cuja representação alegórica normalmente constitui uma leitura crítica da sociedade contemporânea e dos problemas que a atingem. Em seu famigerado romance Ensaio sobre a cegueira [1995], por exemplo, a partir do avassalador evento epidêmico de cegueira branca que assola a sociedade, o autor debate temas referentes à fragilidade das relações humanas e à institucionalização do poder operacionalizados em tempos hodiernos. Já em Ensaio sobre a lucidez [2004] (romance que, pela própria estrutura paralelística do título, mantém vínculos com a obra citada anteriormente), Saramago problematiza os atuais moldes da democracia participativa indireta. Retrata-se nessa obra uma nova epidemia que se alastra pela sociedade, mas agora se trata de votos em branco que inundam as sessões eleitorais de uma cidade, gerando ações autoritárias e violentas dos políticos que detêm o poder estatal. Diante desse acontecimento de feição distópica, as autoridades são deslegitimadas, a população se vê obrigada a criar outras formas de governança e a democracia precisa se reinventar dentro do espaço da cidade. 
As relações estabelecidas entre literatura e política são mais operativas do que se imagina. Consequentemente, os estudos literários também refletem essa propriedade e acabam por imprimir uma considerável carga política no seu exercício de leitura crítica e de proposição teórica. Conforme bem assinala Terry Eagleton, "a história da moderna teoria literária é parte da história política e ideológica da nossa época." (2006, p. 294). No campo da elaboração estética, o espaço é uma das categorias estruturantes do texto literário em que esse viés político pode ser observado com grande facilidade, já que, como não existe olhar neutro, a "nossa percepção do espaço físico é, assim, mediada por valores" (BRANDÃO. OLIVEIRA, 2019, p.69). Deste modo, neste ensaio serão analisadas as propriedades políticas do espaço estruturado no romance Ensaio sobre a lucidez, concedendo especial atenção para a demarcação de fronteiras e para a operacionalização do poder na cidade ficcional.

Na obra em questão, Saramago questiona a democracia, que é a forma de governo mais difundida na sociedade mundial no contexto pósmoderno. $\mathrm{O}$ autor apresenta um quadro político invertido (sobretudo no que se refere à relação entre governantes e governados) e revela uma face velada da democracia, composta por suas fraquezas e vícios. Nas digressões do narrador, surgem questionamentos sobre 0 tipo de comportamento político adotado pelo estado democrático. É neste cenário, no qual todos ficam à mercê de um estado privado e violento, que se desenvolverá a narrativa, produzindo uma provável e plausível metáfora da sociedade pós-moderna imersa em uma cegueira política coletiva.

Assim como os metarrelatos estruturadores da nossa sociedade (LYOTARD, 2011) - tais como a Ciência, a Razão e a Religião -, a democracia surge como algo fundamental para a construção do pensamento e da experiência humana no Ocidente; algo que não se discute e nem se questiona. Debater o conceito de democracia em si não é a questão central da crítica tecida no Ensaio sobre a lucidez, mas sim a forma como os Estados modernos se apropriaram desse sistema político e minaram a participação popular nos processos decisórios do estado, criando um "harmonioso binômio autoridade-obediência à luz do qual floresceram as mais felizes sociedades humanas e sem o qual, como a história amplamente tem demonstrado, nem uma só delas teria sido exequível." (SARAMAGO, 2012, p. 115).

$O$ fato é que existe uma relação direta entre o surgimento da democracia e a constituição da cidade como um espaço social. Sem cidade não existe democracia. Do ponto de vista histórico, na antiguidade grega a democracia dividia terreno com duas outras formas de governo: a monarquia e a aristocracia. Semelhante ao que se vislumbra no romance de Saramago, os primeiros filósofos que se debruçaram sobre o tema já se 
indagavam qual seria a melhor forma de governo. Durante muitos séculos, as respostas foram as mais variadas possíveis, mas a democracia permanecia como uma forma ambivalente e que, por estar ligada ao povo, tinha no seu cerne o verme da sua própria destruição. Assim pensavam Platão e Aristóteles, além dos teatrólogos gregos Aristófanes, Sófocles e Ésquilo. No Império Romano, a concepção acerca da democracia não evoluiu muito, sendo considerada uma forma de governo inviável para os interesses do império, apesar de algumas das suas propriedades terem sido adotadas naquele momento. Após a queda do Império Romano, a democracia desapareceu da discussão e sua efetivação ficou cada vez mais improvável, até que, no século XVI, pensadores como Maquiavel e La Boétie retomam as discussões a respeito do tema.

O salto rumo à democratização dos estados veio com a Revolução Francesa e seus ideais de liberdade, igualdade e fraternidade. $O$ segundo lema da revolução indicava o caminho a ser percorrido pelos Estados modernos e a instituição da economia de mercado, alavancada pela Revolução Industrial que submetia o cidadão comum "tanto ao poder das leis de mercado como ao poder do estado" (ROSENFIELD, 2008, p. 19). A concepção de igualdade sedimenta o ideal democrático, já que qualquer cidadão pode ser o governante, não importando, pelo menos teoricamente, a sua casta ou condição econômica.

Paralelamente ao percurso histórico do sistema democrático no mundo ocidental, é importante destacar algumas particularidades referentes ao próprio conceito de democracia. Em seu livro $O$ que é democracia?, Simone Goyard-Fabre discorre sobre o estatuto desse sistema regimental na atualidade. Na concepção da autora, a democracia:

[...] já não corresponde tanto a um regime político, e sim a um tipo de sociedade caracterizada por uma mentalidade específica. Esta, exposta a ímpetos que muitas vezes constituem abusos, engendra tantas distorções que, em vez do tão esperado progresso da consciência política, é grande a chance de se instalar uma regressão que, pelo trabalho de sapa das paixões já temido por Platão, corre o risco de ser fatal. Diante dos dilemas com que depara, a democracia ameaça desagregar-se, até mesmo nos seus princípios mais profundos. Instalou-se uma 'crise', e há aqueles que se perguntam se não seria necessário um 'novo paradigma' para que a democracia escapasse a aporias mortais. (2003, p. 6).

Em Ensaio sobre a lucidez, Saramago questiona o grau de mecanicidade a que chegou a democracia. Não podemos deixar de 
reconhecer que o direito ao voto foi "uma das mais importantes conquistas operárias do século XIX" (ROSENFIELD, 2008, p. 23). No entanto, o simples ato de votar não efetiva a potencialidade da democracia e tampouco encerra todas as possibilidades de participação democrática. Bem pelo contrário, dissociado de outras intervenções políticas, o ritual do voto apenas engessa a democracia e fortalece os verdadeiros donos do poder deliberativo. As decisões que realmente interferem na vida do cidadão são tomadas em outra esfera de poder e não nas urnas. A partir dessa problemática, Saramago cria um cenário de sublevação popular através da deslegitimação do governo no próprio ato de votar ("A urna estava vazia, pura, imaculada, mas não havia na sala um só eleitor, um único para mostrar, a quem pudesse ser exibida" - SARAMAGO, 2012, p. 12).

Atualmente, a democracia ainda é considerada a forma de governo mais justa que o homem foi capaz de criar. A sua própria base etimológica (do grego demokatía: demos, povo + kratos, poder - portanto, "governo do povo") já justifica as ações dos seus governantes, mesmo que ilegais ou autoritárias. Sabemos, contudo, que a concepção de democracia instituída pelos gregos no século VI a.C. não vigora mais. Nesse sentido, o "governo do povo" permanece mais como um slogan e um discurso que legitima a perpetuação desse sistema entre os povos, do que como uma forma de governo a ser seguida e respeitada.

Historicamente, a democracia divide-se em duas fases: a antiga e a moderna. A democracia antiga está intimamente vinculada à ideia de polis grega, cuja comunidade decidia seu destino em um espaço público, no qual todos os cidadãos livres poderiam participar das tomadas de decisão. Evidentemente, avaliando com distanciamento, logo se percebe que a democracia grega não era um sistema aberto e de plenos direitos, pois nem todos (como escravos e mulheres, por exemplo) eram elegíveis nas tomadas de decisão. Já a democracia moderna está associada ao surgimento do Estado pós-Revolução Francesa; ela não apresenta características similares à democracia antiga, pois não há a mesma participação direta da população nas decisões que o estado deve tomar. Essa transformação se deve ao avanço demográfico das populações e ao próprio crescimento das cidades, fato que gerou uma anomalia na democracia e fez surgir um mecanismo da representatividade. Assim sendo, os espaços públicos foram substituídos por centros administrativos e 0 poder de decisão dos cidadãos foi transformado em delegações nas quais um pequeno número de representantes delibera em nome do povo. $O$ atual sistema de eleição em Portugal e no Brasil é um exemplo notório dessa representatividade que delega $o$ poder e as responsabilidades a um pequeno grupo de governantes. Na prática, o povo fica cada vez mais distante dos centros de decisão e a democracia se reduz ao voto, tornando- 
se fragilizada e mais facilmente corrompida pelo poder econômico. Ao analisar a relação de dependência entre a democracia e os sistemas econômicos, Raymond Williams afirma que o vínculo do Estado com o capitalismo poderá gerar um:

grande fortalecimento de todos os tipos de associação voluntária e informal, desde grupos com interesses específicos e beneficentes até grupos políticos e culturais alternativos e oposicionais. Isso poderia tornar-se, na prática, a realização dos poderes sociais e culturais plenos de uma sociedade civil, em oposição à sua apropriação e marginalização pelas corporações e pelo Estado. (WILLIAMS, p. 154).

Há uma relação significativa entre essa ideia de que a democracia é a forma de governo mais adequada aos valores morais cultuados no mundo ocidental e as mudanças histórico-sociais instituídas após a Segunda Guerra Mundial, que oportunamente chamou-se de PósModernidade. Neste novo contexto, a democracia ganha força e torna-se um baluarte no qual os povos devem se apoiar para não verem ressurgir regimes fascistas e cenas de genocídios. No entanto, essa concepção adquire muito mais eficácia no campo do discurso dos governos do que na prática social e política, haja vista a grande quantidade de governantes autoritários que utilizam a democracia como pano de fundo para suas ações criminosas e ilegítimas. No romance aqui analisado, essas ações aparecem sob a máscara do abandono e da ameaça:

Agora sois uma cidade sem lei. Não tereis aqui um governo para vos impor o que deveis e o que não deveis fazer, como deveis e como não deveis comportar-vos, as ruas serão vossas, pertencem-vos, usai-as como vos apeteça, nenhuma autoridade aparecerá a cortar-vos o passo e a dar-vos o bom conselho, mas também, atentai bem no que vos digo, nenhuma autoridade virá proteger-vos de ladrões, violadores e assassinos, essa será a vossa liberdade, desfrutai dela. (SARAMAGO, 2012, p. 107).

Na trama articulada por Saramago, a democracia plena naturalmente leva a coerção da liberdade; ser livre e igualitário acarreta riscos que talvez devessem ser evitados. Casos como esses podem ser encontrados nas democracias populistas da América do Sul e imperialistas da Europa e América do Norte de meados do século XX, algumas delas ainda em vigor, conforme bem afirmaram Steve Levitsky e Daniel Ziblatt 
no seu livro Como as democracias morrem (2017).

Uma questão de suma importância para o estabelecimento do discurso democrático (ou da "narrativa hegemônica", nas palavras de Lyotard) foi a sua associação aos mercados capitalistas pelo princípio dos "indivíduos egoístas" ou dos "consumidores ávidos" - expressões empregadas por Jacques Rancière (2014) para designar o "homem democrático". Esse vínculo instituído entre a democracia e o capitalismo tornou-se tão visceral, que a tentativa de eliminar o segundo levou inevitavelmente ao desaparecimento do primeiro, como verificamos nos países da ex-União Soviética ou em Cuba. Em parte, isso se deve ao fato de o mercado, como segmento determinador da modernidade, ter se constituído parte significativa do nosso próprio ser (ROSENFIELD, 2008).

De acordo com o filósofo Slavoj Zizek, para nos adequarmos as restrições da realidade, vivemos um momento de perda dos sonhos e apagamento das utopias. E "a razão disso é que vivemos numa época póspolítica de naturalização da economia: em regra, as decisões políticas são apresentadas como questões de pura necessidade econômica; [...]" (ZIZEK, 2011, p. 12-13). Dessa forma, transforma-se a democracia no reino do consumidor narcisista, que vai modificando suas escolhas eleitorais conforme varia seus prazeres íntimos (RANCIÈRE, 2014). O erro dos operacionalizadores da democracia atual foi subjugar as limitações impostas pelo discurso político, acreditando encerrar sobre si, de maneira inquestionável, a verdade e a liberdade dos povos. Assim sendo, eles deveriam reconhecer as suas limitações e os seus equívocos, ainda mais quando as populações forem esclarecidas do seu papel e da sua força propulsora.

Essa conjuntura política foi formulada na sangrenta história do século $X X$, capaz de profetizar seu próprio fim com a possibilidade do holocausto nuclear. Com efeito, a violência no século XX cresceu em igual proporção ao desenvolvimento científico e tecnológico, transformando em palavras vãs o bem-estar social que ele prometia proporcionar. Consequentemente, esse quadro acaba pondo em descrédito os metarrelatos e questionando os alicerces da própria modernidade. Zizek ainda argumenta que a queda do Muro de Berlim instaurou uma nova mentalidade na sociedade ocidental, pois há uma "crença de que a democracia liberal, em princípio, vencera, de que o surgimento de uma comunidade liberal global estava logo ali na esquina [...]" (ZIZEK, 2011, p. 17). No fim das contas, todo esse sistema foi paulatinamente se revelando no abismo das desigualdades sociais.

Está claro que a escolha de um governante através do voto não resolve os problemas de uma população, pois as forças econômicas que atuam de maneira global engessam e chegam a impossibilitar avanços 
sociais, que até então eram propostas de homens públicos. O capitalismo está fazendo desaparecer a distinção entre o público e o privado, e a democracia passou a ser uma forma de manter a ordem diante de uma conjuntura político-econômica bem mais profunda e fora de alcance das populações.

Em obras como $A$ busca da política (2000) e $A$ vida fragmentada: ensaio sobre moral pós-moderna (2007), o sociólogo polonês Zygmunt Bauman também se mostra bastante cético em relação aos rumos tomados pela política em nossa época, que é muito impactada pelas modificações no campo econômico e do conhecimento. Bauman argumenta que:

Num mundo que se globaliza rapidamente, em que grande parte do poder - a parte mais importante - foi retirada da política, essas instituições não podem fazer muito para fornecer segurança, ou garantias.

[...] Os poderes mais poderosos fluem ou flutuam e as decisões mais decisivas são tomadas num espaço distante da ágora ou mesmo fora do espaço público politicamente institucionalizado.

[...] o verdadeiro poder ficará à distância segura da política

e a política permanecerá impotente para fazer o que se espera da política [...] (BAUMAN, 2000, p. 13-14).

As questões discutidas em Ensaio sobre a lucidez mantêm fortes pontos de convergência com as reflexões do filósofo polonês expostas acima, especialmente no que se refere ao fato de o Governo, rechaçado pela população nas urnas, passar a decidir sobre os destinos da cidade. Mesmo sem legitimidade para atuar como governante, ele emprega meios totalitários para subjugar a população, conforme fica evidente no ataque ordenado à estação de metrô, resultando em uma verdadeira carnificina e no posterior estabelecimento do estado de sítio:

À mesma hora que o primeiro-ministro aparecia na televisão a anunciar o estabelecimento do estado de sítio invocando razões de segurança nacional resultantes da instabilidade política e social ocorrente, consequência, por sua vez, da acção de grupos subversivos organizados que reiteradamente haviam obstaculizado a expressão eleitoral popular, unidades da infantaria e da polícia militarizada, apoiadas por tanques e outros carros de combate, tomavam posição em todas as saídas da capital e ocupavam as estações de caminho de ferro. (SARAMAGO, 2012, p. 74). 
No excerto transcrito acima, observamos que os diferentes mecanismos de poder invadem de forma incisiva o território citadino, uma vez que eles alcançam tanto o segmento material (marcado pela presença de tanques e infantaria) quanto o virtual (assinalado pelo comunicado emitido pela rede televisiva) do espaço. Assim sendo, o controle da população é exercido simultaneamente pela manipulação do discurso e pela ação opressiva. Dados de natureza antagônica se conectam, portanto, para reforçar a eficácia da tarefa controladora, assegurando a manutenção de uma política caracterizada pela força e pelo ludíbrio.

Em um interessante estudo sobre os regimes políticos da atualidade, Denis Rosenfield elenca algumas características da democracia contemporânea. Dentre elas, podemos citar o surgimento de grupos políticos ideologicamente estruturados que barram a participação política direta das populações, a autoridade ilimitada que tais grupos acabam adquirindo e, o que nos parece mais emblemático, a ideia de que "a violência tomará uma forma política e institucional, tornando-se uma forma de governo sem nenhuma subordinação às leis ou regras previamente estabelecidas." (2008, p. 70). É exatamente esse panorama que se observa em Ensaio sobre a lucidez quando o governo decreta estado de sítio e restringe os direitos individuais:

Houve também pessoas que se limitaram a desligar o aparelho de televisão quando o primeiro-ministro terminou e depois, enquanto não iam para a cama, se entretiveram a falar das suas vidas, e outras houve que passaram 0 resto do serão a rasgar e a queimar papéis. Não eram conspiradores, simplesmente tinham medo. (SARAMAGO, 2012, p. 42).

Logo percebemos que, diante da barbárie assegurada, qualquer alternativa pretendida leva inevitavelmente ao transtorno e ao fracasso. De imediato, o medo toma conta dos corpos e os mutila por dentro. O corpo é o primeiro espaço que habitamos, de modo que a sua perfeita saúde reflete o bem-estar do sujeito. Ao ter seu corpo cindido pelo medo, o homem se desestabiliza, pois diante da incerteza do estar no mundo, ele também vê abaladas as estruturas que constituem o seu ser para o mundo. Dessa forma, do sonho de liberdade restam apenas homens fragmentados que sucumbem em meio à pressão política exercida sobre a fragilidade de seus corpos.

É importante destacar, contudo, que Saramago contrapõe o cenário agonal da cidade sitiada (vigiada pelas forças armadas e em constante estado de tensão) à tranquilidade com que os cidadãos tomam suas decisões, sem alarde, sem violência e de forma extremamente organizada. 
A ausência de um poder central e a aparente tranquilidade da cidade causam estranhamento nas personagens que investigam o motivo da votação em branco, como podemos observar no trecho abaixo:

[...] Homem, tem calma, não há nenhum motivo para preocupação, olha para estas ruas, repara como a cidade está sossegada, tranquila, Pois é justamente isso que me inquieta, senhor comissário, uma cidade como esta, sem autoridades, sem governo, sem vigilância, sem polícia, e ninguém parece importar-se, há algo muito misterioso que não consigo entender, [...]. (SARAMAGO, 2012, p. 250).

A circunstância misteriosa a que alude o personagem pode ser perfeitamente interpretada como uma espécie de dialética do vazio: não se vê nem se ouve nada, mas se pressente o perigo eminente; há calmaria por todos os lados, mas os corpos se obrigam a ficar em permanente estado de alerta. Transitando em um mundo em pleno descompasso, marcado por tensões dissimuladas, os cidadãos se jogam em espaços arruinados pelo senso de autoridade e pela tirania. Diante de tais circunstâncias, transformam-se em nômades no seio da própria pátria. Ou o que ainda é pior: estão completamente à deriva em meio a um território assinalado por massivas disputas políticas.

\section{ESPAÇO, CIDADE E PODER}

No romance Ensaio sobre a lucidez, a cidade/capital que se rebela contra a ordem estabelecida não é nominalmente referenciada. No entanto, pela exposição da sua sintaxe e morfologia urbana (composta por ruas movimentadas, cafés, estações de metrô, prédios comerciais e apartamentos), pela disposição dos objetos e dos cômodos nas casas e, principalmente, pela descrição dos hábitos culturais da população que nela habita, podemos inferir que a condição urbana textualizada por Saramago toma por referência simbólica qualquer cidade ocidental que tenha a democracia como sistema político e o capitalismo como sistema econômico.

As relações estabelecidas entre a cidade real e a cidade ficcional são mais densas e problematizadas do que aparentam ser. Em princípio, há uma intervenção mútua entre esses dois componentes, de modo que a cidade real fornece um modelo para a composição do espaço literário e a cidade ficcional acaba atualizando simbolicamente o espaço que serviu de base para sua construção. De uma forma ou de outra, a transposição de conteúdos não é operacionalizada de maneira direta e livre dos agentes mobilizados no processo de composição literária; bem pelo contrário, há sempre uma 
mediação de estruturas e valores que reorganiza a imagem citadina e lhe imprime um semblante renovado. Desse modo, ainda que o escritor português tente a todo custo camuflar a referencialidade espacial em sua obra, dados de ordem social, histórica, cultura e política sempre escapam em meio ao processo criador.

Esse aspecto foi densamente examinado pela pesquisadora argentina Beatriz Sarlo em seu livro $A$ cidade vista - mercadorias e cultura urbana (2014). Na concepção da autora:

A cidade escrita pode ter como referências cidades reais. Bem se sabe que a cidade foi o espaço literário característico do realismo e do naturalismo, que a pressupunham mesmo que não a representassem como cenário, mas lá estava ela como horizonte desejável ou círculo infernal. E é uma obsessão da literatura do século $X X$ e da que está sendo escrita hoje. A cidade real faz pressão sobre a ficção por sua força simbólica e seu potencial de experiência, mesmo em textos que não se ocupam deliberadamente dela. (SARLO, 2014, p. 140).

Podemos afirmar, portanto, que a cidade talvez seja o objeto mais habitual, regular e contundente da literatura. Mais do que isso, em vários momentos da História literária, ela parece subsidiar o processo criativo, ditando princípios estruturais e modelos específicos de figuração. Não se estranha, pois, o fato de o pesquisador italiano Giulio Carlo Argan (2005) ter escrito um livro defendendo a tese de que a história da cidade (com todo o seu processo evolutivo) interfere diretamente na história da arte e no desenvolvimento das formas artísticas. A verdade é que através de figuração da cidade na literatura é possível discutir temas da mais variada ordem.

No âmbito narrativo, a cidade ficcional é percebida e experienciada pelas personagens através do corpo e de seus gradientes sensoriais. Para vivenciar a arquitetura citadina, o sujeito é impelido não apenas a olhar para as formas urbanas, mas a senti-las sinestesicamente. Com efeito, todo o seu corpo denuncia a presença do espaço: imagens, texturas, ruídos, odores e sabores se juntam para compor uma concepção de cidade. Como se não bastasse, o resultado desse processo ainda é mediado pelos mecanismos mentais da percepção, que pressupõe recortes, escolhas, preferências pessoais etc. Evidentemente, em determinados casos, alguns recursos serão mais explorados do que outros, mas isso não significa que os dados menos evidentes estejam ausentes do processo de composição. Vejamos uma passagem extraída de Ensaio sobre a lucidez. 
com a intenção de atalhar caminho, se lhe deparasse com modesto café à antiga, desses que abrem cedo porque 0 proprietário não tem mais nada que fazer e onde os clientes entram para se certificarem de que as coisas, ali, continuam nos seus lugares de sempre e o sabor do bolo de arroz emana da eternidade. (SARAMAGO, 2012, p. 347).

No fragmento acima, a personagem vivencia o espaço através dos sentidos humanos da visão, do tato e do paladar. Ainda que não sejam explicitamente mencionados, também podemos intuir o cheiro do bolo (olfato) e o rumor quase silencioso do café frequentado pelo personagem (audição). Mas tem de se mencionar que, da forma como foram retratadas, essas dimensões corpóreas tiram o sujeito da materialidade do espaço e o lançam na temporalidade da vida. Assim, ele passa a habitar um espaço mítico, no qual o peso da experiência lhe confere uma sensação de pertencimento e, por conseguinte, de segurança e poder.

É preciso ressaltar que existe uma divisão muito clara no enredo de Ensaio sobre a lucidez. A primeira parte da narrativa retrata os macroespaços da obra, como a capital rebelada e as demais cidades do entorno, constituindo uma coordenada espacial de interioridade (interior $x$ exterior) e uma relação dialética de ordem e subversão. Na segunda parte, o narrador focaliza os espaços mais íntimos da cidade, tais como a moradia dos investigadores, o apartamento dos investigados (espaços privados), as ruas e a praça (espaços públicos). Por questões didáticas, veremos neste ensaio considerações apenas sobre os macroespços da obra.

A cidade apresentada pelo narrador figura inicialmente como um espaço de convivência, mas ela vai paulatinamente se transformando em um campo de batalhas e disputas políticas. Ou seja, a cidade se converte em um verdadeiro território a ser conquistado, uma vez que o "território é o espaço dominado por algum tipo de poder, é o espaço enfocado do ponto de vista político ou da relação de dominação-apropriação." (BORGES FILHO, 2007, p. 28). O poder institucionalizado na figura do Estado é questionado durante a votação em branco; o povo já não mais deseja entregar o controle da sociedade nas mãos dos governantes. Sem eleitos, sem governo. Como o poder não foi pacificamente entregue aos governantes através do voto, ele vai ser tomado e utilizado coercitivamente contra essa mesma população.

Uma das primeiras medidas tomadas pelos poderosos foi 0 esvaziamento das esferas institucionais do poder. Assim, evacuaram da cidade toda forma de poder institucionalizado, como a polícia e o governo. Posteriormente, a segunda medida adotada foi o estabelecimento do estado de sítio com restrições de direitos. Nesse instante, a cidade passa a ser 0 espaço da coerção exercida de fora para dentro. Há um paradoxo nisso tudo, 
pois os poderes instituídos agem contra a própria população e a cidade se torna alvo de ataques, evidenciando que não são precisamente as instituições que concebem e organizam a condição urbana, já que os habitantes vivem normalmente mesmo sem um centro de poder.

No decorrer da narrativa, o governo ilegítimo abandona da cidade com o intuito de largar a população à sua própria sorte, mas a reação popular foi contrária ao que se esperava. A cidade não se tornou caótica em função da ausência de um poder centralizador; bem pelo contrário, ela se tornou mais fraterna:

As ruas, até aí praticamente desertas, fechado o comércio quase todo, quase vazios os autocarros que passavam, encheram-se de gente em poucos minutos. Os que tinham ficado em casa debruçavam-se às janelas para ver 0 concurso, palavra que não quer dizer que as pessoas caminhassem todas na mesma direção, eram antes como dois rios, um a subir, outro a descer, e acenava-se de um lado para o outro como se a cidade estivesse em festa, como se fosse feriado municipal, por ali não se viam ladrões nem violadores nem assassinos, ao contrário dos mal-intencionados prognósticos do presidente fugido. (SARAMAGO, 2012, p. 109).

O desmonte das estruturas de poder faz com que a cidade aos poucos recomponha a perfeita saúde de sua condição urbana. No trecho transcrito acima, a imagem da vida é estruturalmente representada pelo próprio movimento dos elementos que compõem a cena (o abrir de janelas, os transeuntes, a correnteza dos rios e a imagem dos festejos). Em outras palavras, a cidade passa a ter um corpo vivo.

$\mathrm{Na}$ tentativa de compreender o motivo que levou a maioria absoluta dos eleitores a votar em branco, o Estado inicia uma investigação. Muitos habitantes foram interrogados e até mesmo torturados para que revelassem a causa do voto ou para que confirmassem uma possível orquestração internacional com o intuito de desestabilizar o país. Vejamos um trecho que relata a tortura praticada:

No fim dir-te-ão que mentiste, tu negarás, jurarás que disseste a verdade, toda a verdade e só a verdade, e talvez seja certo, não mentistes, o que acontece é que és uma pessoa nervosa, de vontade forte, sim, como uma espécie de trémulo junco que a mínima aragem faz estremecer, tornarão a atar-te à máquina e então será muito pior, perguntar-te-ão se estás vivo e tu, claro está, responderás que sim, mas teu corpo protestará, desmentir-te-á, o 
tremor do teu queixo dirá que não, que estás morto, e se calhar tem razão, talvez, antes de ti, o teu corpo saiba já que te vão matar. (SARAMAGO, 2012, p. 60).

Mais uma vez, a imagem do corpo desponta como elemento de destaque no contexto dessa discussão. A situação também não poderia ser diferente, pois segundo bem postula Michel Foucault (2019) em seu estudo sobre a Microfísica do poder, o adestramento e o controle dos corpos constitui uma das formas mais eficazes de produção e manutenção do poder disciplinar. Com efeito, de nada adianta manter a consciência viva se o corpo estiver exausto e falido. Dessa maneira, são as intervenções feitas no corpo do personagem que dão a exata medida do seu grau de rendição ao sistema opressor; quando o indivíduo perde o controle do próprio corpo, ele cede aos desígnios do inimigo.

É por esse motivo que a abordagem punitiva dos governantes deixa de focar a coletividade da população e passa a ser realizada de forma mais individualizada, constantemente recorrendo à prática ilegal da tortura dos corpos. Após realizar uma série de atos antidemocráticos (como os interrogatórios arbitrários, a tortura, o decreto de estado de sítio e até mesmo um atentado à bomba em uma estação de trem), o governo passa a procurar o líder do movimento do voto em branco. Sabemos, contudo, que esse líder não existe.

Na ausência de um governo, as ruas da cidade passam a ser o local de encontro, reunião e manifestação. Historicamente, a imagem da rua comporta essa fisionomia coletiva e popular, uma vez que ela já foi palco de grandes revoluções. Enfim, é na rua que as muitas experiências individualizadas se encontram, fundem-se e transformam-se em um único corpo social. De feitura mais democrática, a rua unifica a diversidade e a transforma em artilharia. Deslocar-se pelas ruas corresponde, portanto, a uma demonstração de poder da população.

Como se não bastassem os diversos atos de cisão e isolamento planejados e executados com o intuito de sufocar a vida social da cidade, em um determinado ponto da narrativa sugere-se a construção de um muro, símbolo máximo da divisão, que separaria por completo a capital do restante do país:

[...] o senhor ministro da defesa dir-me-á que tem patrulhas no terreno, que tem sensores electrónicos instalados ao longo da fronteira, e eu não me permitirei duvidar da eficácia relativa desses meios, porém, é meu parecer que uma contenção que se pretenda total só poderá ser conseguida pela construção de um muro a toda volta da capital, um muro intransponível feito com placas 
de cimento, calculo que uns oito metros de altura, [...]. (SARAMAGO, 2012, p. 188).

Para concluirmos a análise, ainda é preciso mencionar rapidamente dois espaços que, dada a sua natureza topofílica, contrapõe-se à atmosfera agonal que reina por quase toda a cidade: trata-se da praça e da casa da mulher do médico. Esses espaços de conforto oferecem resistência simbólica aos ambientes de dor e opressão e, de certo modo, proporcionam ao leitor um momento de placidez em meio a uma narrativa tão densamente marcada pela tragicidade. Embora caracterizado por termos negativos, há um jardim localizado em alguma parte da cidade que também possui semelhante função. Nesse lugar acontecem os encontros entre a mulher do médico e 0 comissário enviado pelo governo. Após o diálogo estabelecido com a moça, o comissário muda de ideia em relação à investigação e passa a agir em desacordo com as ordens governamentais. A casa, a praça e o jardim são, portanto, espaços de resistência que garantem a manutenção da democracia em seu estado mais pleno, pois neles ainda é possível assegurar o desejo do povo. Como esses espaços estão imunes às intervenções governamentais, eles acabam por revelar uma ordem mais justa e equilibrada a que toda a população da cidade almeja alcançar.

Diante de todo o exposto, podemos afirmar que o Ensaio sobre a lucidez apresenta uma crítica ao modo como a democracia está sendo implementada nos estados, normalmente amparada por uma prática de poder coercitivo que apenas limita a atuação da população no espaço da cidade. A relação estabelecida entre espaço, democracia e poder se torna ainda mais evidente quando constatamos que os espaços na narrativa saramaguiana praticamente não assumem posições fixas. Aqui não existe espaço com características definidas e imutáveis; a própria vivência das personagens constantemente transforma a imagem da cidade. Desse modo, é como se o exercício fenomenológico da percepção promovesse as mudanças que foram negadas pelos governantes da cidade.

\section{REFERÊNCIAS}

AGUIAR E SILVA, Vitor Manuel. Teoria da Literatura. 8. ed. Coimbra: Almedina, 1993.

AGUILERA, Fernando Gómez (Org.). As palavras de Saramago. Catálogo de reflexões pessoais, literárias e políticas. São Paulo: Companhia das Letras, 2010. 
ARGAN, Giulio Carlo. História da arte como história da cidade. 5 ed. São Paulo: Martins Fontes, 2005.

BAUMAN, Zygmunt. A Vida fragmentada: ensaio sobre Moral pósmoderna. Lisboa: Relógio D'água Editores, 2007.

BAUMAN, Zygmunt. Amor líquido: sobre a fragilidade dos laços humanos. Rio de Janeiro: Jorge Zahar, 2004.

BAUMAN, Zygmunt. Em busca da política. Rio de Janeiro: Jorge Zahar Ed, 2000.

BENJAMIN, Walter. A obra de arte na era da reprodutibilidade técnica. In: . Magia e técnica, arte e política. São Paulo: Brasiliense, 1994.

BERLINER, Cláudia; GOYARD-FABRE, Simone. O que é democracia? São Paulo: Martins Fontes, 2003.

BRANDÃO, Luis Alberto. Teorias do espaço literário. São Paulo: Perspectiva, 2013.

BRANDÃO, Luis Alberto. OLIVEIRA, Silvana Pessôa de. Espaço e literatura. In: Sujeito, tempo e espaço ficcionais. 2. ed. São Paulo: Martins Fontes, 2019.

BORGES FILHO, Ozíris. Espaço e Literatura: introdução à topoanálise. São Paulo: Ribeirão gráfica e editora, 2007.

EAGLETON, Terry. Teoria da literatura: Uma introdução. São Paulo: Martins Fontes, 2006.

FERRAZ, Salma. Dicionário de personagens da obra de José Saramago. Blumenau: Edifurb, 2012.

FOUCAULT, Michel. Microfísica do poder. 9. ed. Rio de Janeiro/São Paulo: Paz \& Terra, 2019.

HUTCHEON, Linda. Poética do pós-modernismo. Rio de Janeiro: Imago. 1991.

LEVITSKY, Steven; ZIBLATT, Daniel. Como as democracias morrem. Rio de Janeiro: Zahar, 2018.

LYOTARD, Jean-François. A condição pós-moderna. 14. ed. Rio de Janeiro: José Olympio Editora, 2011.

RANCIÈRE, Jacques. 0 ódio à democracia. São Paulo: Boitempo, 2014.

ROSENDIELD, Denis L. O que é democracia. São Paulo: Brasiliense, 2008. 
SANTIAGO, Silviano. A explosiva exteriorização do saber. In: LYOTARD, Jean-François. A

condição pós-moderna. 14. ed. Trad. Ricardo Corrêa Barbosa. Rio de Janeiro: José Olympio

Editora, 2011. p. 125-131.

SANTOS, Boaventura de Sousa. Pela mão de Alice: O social e o político na pós-modernidade. São Paulo: Cortez, 2001.

SARAMAGO, José. Ensaio sobre a Cegueira. São Paulo: Companhia das Letras, 2008.

. Ensaio sobre a lucidez. São Paulo: MEDIAfashion, 2012.

SARLO, Beatriz. A cidade vista - mercadorias e cultura urbana. São Paulo: WMF Martins Fontes, 2014.

SILVA, Teresa Cristina Cerdeira da. José Saramago - Entre a história e a ficção: Uma saga

de portugueses. Lisboa: Publicações Dom Quixote, 1989.

WILliAMS, Raymond. Política do Modernismo: contra os novos conformistas. São Paulo: Editora Unesp, 2011.

ZIZEK, Slavoj. 0 ano em que sonhamos perigosamente. São Paulo: Boitempo, 2012.

ZIZEK, Slavoj. Primeiro como tragédia, depois como farsa. São Paulo: Boitempo, 2011

Recebido em: 30/11/2021

Aceite em: 08/12/2021 